\title{
A teoria, a prática, o professor e a educação ambiental: algumas reflexões
}

\section{Theory, practice, teachers and environmental education: some reflections}

\author{
Lucas André Teixeira * \\ Marília Freitas de Campos Tozoni-Reis * \\ Jandira Líria Biscalquini Talamoni ${ }^{* * *}$
}

\begin{abstract}
Resumo: A aceleração dos desenvolvimentos econômico e científico causada pelo sistema de produção e pela ciência mecanicista fez surgir novas estruturações de poder e novos problemas políticos e sociais, inclusive os ambientais, consolidando-se, assim, um período de crises disseminadas nos vários âmbitos da sociedade. Em tal conjuntura, a reflexão sobre as principais causas da problemática ambiental apresenta-se como necessidade para o campo da educação ambiental. Considerando, portanto, que a atual crise ambiental está diretamente relacionada ao modo e aos meios de produção do sistema capitalista, entende-se que as iniciativas no âmbito da educação ambiental devem refletir, a partir de um processo histórico e dialético, sobre o que preconiza a sociedade do capital. Diante das diversas concepções e abordagens teórico-práticas existentes na educação ambiental, os princípios da educação ambiental crítica podem criar condições para o enfrentamento da crise estrutural que estamos vivenciando, a partir do processo educativo. Entendida como um processo político de apropriação crítica e reflexiva de conhecimentos, atitudes, valores e comportamentos, que tem como objetivo contribuir para a construção de uma sociedade sustentável do ponto de vista ambiental e social, pretendemos articulá-la às formulações teóricas da Pedagogia Histórico-Crítica , com vistas a apresentar uma reflexão que contribua para o enfrentamento pedagógico da questão ambiental, especialmente no que diz respeito à formação dos professores que desenvolvem projetos no âmbito escolar. Assim, o presente estudo objetiva evidenciar as contribuições da filosofia da práxis na formação do educador ambiental, tendo como fundamentação os pressupostos teóricos inseridos na vertente da educação ambiental crítica.
\end{abstract}

Palavras-chave: Educação ambiental. Formação de professores. Práxis pedagógica.

Abstract: The acceleration of economic and scientific development caused by the production system and mechanistic science, have created new power structures and new political and social problems, including environmental ones, consolidating a period of widespread crisis in different spheres of society. In this context, reflection about the major causes of environmental problems is necessary in the field of environmental education. Therefore, considering that the current environmental crisis is directly related to the mode and the devices of production of the capitalist system, initiatives on environmental education should reflect, from a historical and dialectical process, on what is advocated by capitalist

\footnotetext{
* Mestre em Educação para a Ciência pela Universidade Estadual Paulista Júlio de Mesquita Filho (UNESP/Bauru). E-mail: <teixeira_geo@hotmail.com>.

** Professora Livre Docente da Universidade Estadual Paulista Júlio de Mesquita Filho (UNESP/Botucatu). E-mail: <mariliaedu@ibb.unesp.br>.

**** Professora da Universidade Estadual Paulista Júlio de Mesquita Filho (UNESP/Bauru). E-mail: <talamoni@fc.unesp.br>.
} 
society. Considering the various theoretical-practical concepts and approaches in environmental education, the principles of Critical Environmental Education can provide conditions to confront the structural crisis that we are facing, through the educational process. It is a political process of reflection and critical appropriation of knowledge, attitudes, values and behaviors that aims to contribute to build a sustainable society from the social and environmental points of view. We intend to articulate it through the theoretical formulations of Historical-Critical Pedagogy with the purpose of presenting a reflection that may contribute to a pedagogic response to environmental issues, especially regarding the formation of teachers who develop projects in schools. Thus, this present study intends to highlight the contributions of the philosophy of praxis in the formation of environmental educators, grounded in theoretical aspects of Critical Environmental Education.

Keywords: Environmental education. Teacher training. Pedagogical praxis.

\section{Introdução}

A educação ambiental, como campo teórico em construção, tem sido apropriada de forma diferenciada por diversos atores, com discursos e referenciais teóricos variados, propondo ou oferecendo diversas maneiras de conceber e praticar a ação educativa nesse campo.

Numa outra dimensão, diversos documentos oficiais, internacionais e nacionais valorizam o papel da educação ambiental diante da preocupação com a problemática ambiental, principalmente no tocante à degradação dos "recursos naturais" do planeta. Todos esses atores sociais reconhecem na educação ambiental uma das possibilidades de proporcionar a melhoria na qualidade de vida a partir de ações educativas que oportunizem mudanças nas relações entre o homem e o meio sócio-ambiental.

Para se pensar a educação ambiental, faz-se necessário inseri-la no horizonte educativo. Dessa maneira, entendendo-a como educação e, portanto, como ação política, a educação ambiental não é considerada uma atividade neutra, pois é praticada por sujeitos que sofrem condicionantes biológicos, culturais, sociais, políticos e históricos. Tais condicionantes reproduzem diferenças conceituais que podem ser resumidas como: a educação ambiental para mudança de comportamentos - disciplinatória e moralista; voltada à sensibilização ambiental - ingênua e imobilista; centrada na ação - ativista e imediatista; como transmissão de conhecimentos ecológicos - racionalista e instrumental; e como um processo de conscientização - política-transformadora (TOZONI-REIS, 2007). Cada uma dessas abordagens tem referenciais epistemológicos, filosófico-políticos e pedagógicos diferentes, que, quase sempre, são determinados pela organização da sociedade.

Tal polissemia de abordagens coloca a necessidade de se refletir sobre os ditames que fundamentam o pensamento hegemônico que preconiza a reprodução da ordem que está posta na sociedade atual. Nessa ótica, para refletirmos sobre a problemática ambiental na atualidade, é oportuno recuperar uma das formulações elaboradas por Gramsci (1995), quando este discute a função dos intelectuais que estão a serviço de tal ordem: "por isso é necessário conhecer exatamente o modo de pensar e a ideologia destes intelectuais para melhor entender sua organização de 
hegemonia cultural e moral, a fim de destruíla ou assimilá-la” (GRAMSCI, 1995, p. 101).

Não obstante, no decorrer do século $\mathrm{XX}$, a preocupação com as questões ambientais tomou vulto em consequência das transformações que a Revolução Industrial trouxe para a organização da produção, do consumo e da reprodução da vida. Esse sistema de produção, articulado à ciência mecanicista, promoveu os desenvolvimentos econômico e científico num ritmo espantosamente acelerado. A humanidade entrou na modernidade com novas estruturações de poder e, dessa forma, com novos problemas políticos e sociais, entre eles, o ambiental (TOZONI-REIS, 2004).

Esse espectro que rondou a modernidade acabou por se consolidar em um período de crises (SANTOS, 1994) ao longo da contemporaneidade, disseminandose em diversos âmbitos da sociedade. Com efeito, tal conjuntura coloca para o campo da educação ambiental a necessidade de refletirmos sobre as principais causas da problemática ambiental no cenário mundial.

Consideramos que os motivos causais da crise ambiental estão diretamente relacionados ao modo e aos meios de produção do sistema capitalista, que determinaram e determinam a apropriação e a degradação do espaço sócio-ambiental. Entendemos que qualquer iniciativa no âmbito da educação ambiental deve refletir, a partir de um processo histórico e dialético, sobre os ditames que são preconizados pela sociedade do capital.

Assim, diante das diversas concepções e abordagens teórico-práticas existentes quanto ao modo de conceber a educação ambiental, acreditamos que, a partir do processo educativo, os princípios da educação ambiental crítica podem criar condições para o enfrentamento da crise estrutural que estamos vivenciando a cada dia, resultante do modo de produção capitalista. Logo, entendemos a educação ambiental crítica como um processo político de apropriação crítica e reflexiva de conhecimentos, atitudes, valores e comportamentos que tem como objetivo a construção de uma sociedade sustentável do ponto de vista ambiental e social - a educação ambiental transformadora e emancipatória. (TOZONI-REIS, 2007, p. 179)

\section{Contextualizando as práticas educativas ambientais no âmbito escolar}

Não é raro observarmos uma substancial produção de projetos, pesquisas e propostas teóricas de educação ambiental nas escolas, universidades, comunidades e outros segmentos da sociedade, muitas vezes realizadas por ONGs, empresas privadas e pelo Poder Público. No entanto, grande parte delas não consegue problematizar criticamente as situações que tematiza; e, por outro lado, diversos estudos verificam que esses problemas ambientais, além de serem evidentes e graves, se intensificam a cada momento.

No âmbito acadêmico, essa possibilidade é evidenciada na medida em que se pode observar a carência de uma fundamentação teórico-metodológica nas pesquisas em educação ambiental, ilustrada pelos dados levantados por Novicki (2004, apud LOUREIRO, 2006), que indicam que 58\% das pesquisas em educação realizadas no Rio de Janeiro não apresentam metodologia clara e que 30\% realizam uma "miscelânea teórica”.

Ainda em relação a essa questão, cabe recuperar os resultados de um estudo que realizamos no ano de 2007, 
intitulado "Referenciais teóricos da pesquisa em educação ambiental em trabalhos acadêmicos" (TEIXEIRA et al., 2007), no qual identificamos que $40,5 \%$ da fundamentação teórica dos trabalhos analisados baseavam-se em documentos oficiais. Tal fato contribui para que as ações educativas ambientais acabem resultando em ações que se esvaziam de sentido, ocorrendo assim uma perda de densidade na compreensão do que caracteriza a educação ambiental.

No que se refere ao âmbito da educação ambiental no contexto escolar, Guimarães (2006), ao analisar as práticas educativas dos professores, verificou que aquelas práticas que objetivam ações e resoluções de problemas ambientais pontuais, no contexto em que a escola está inserida, são mais comuns. Essa constatação pode revelar a interpretação de que o objetivo do processo educativo é solucionar problemas, ao invés de ser considerado um processo de enfrentamento sócio-histórico do problema.

O mesmo autor constatou que a prática pedagógica dos professores que realizam ações educativas reconhecidas como educação ambiental apresenta-se geralmente fragilizada. Isso se deve, em grande parte, à falta de uma reflexão sobre o processo educativo e sobre a educação ambiental numa perspectiva crítica e politizada, o que leva o professor a reproduzir o fazer pedagógico da educação ambiental convencional, que é reforçada pela racionalidade hegemônica, caindo na "armadilha paradigmática". Ou seja, "adotando uma visão ingênua por ser reduzida, não percebendo os conflitos e as relações de poder que engendram a realidade sócio-ambiental” (GUIMARÃES, 2006, p. $25)$ e ficando, portanto, preso aos paradigmas da sociedade atual.
Consideramos que o objetivo do processo educativo, em uma perspectiva crítica, é promover ações que visam à superação dos problemas ambientais por meio de um processo histórico, crítico e reflexivo sobre os fatores que determinam a organização da sociedade, objetivando sua transformação, e não resolver um problema pontual desvinculado de outros determinantes estruturais.

Nesse sentido, o que determina tais distorções é, justamente, a falta de uma reflexão filosófico-política sobre as causas históricas da crise ambiental, já que grande parte dessas propostas está fundamentada nos mesmos pressupostos e concepções que deram origem a esses problemas e, assim, terminam por incorrer no que Grün chamou de "pedagogia redundante":

Tais situações, em se tratando de educação ambiental, tomam a forma de uma pedagogia redundante, ou seja, uma pedagogia que não tem dinamismo compreensivo. Em certo sentido, um discurso ambientalista pautado pela pedagogia redundante é um discurso que nega aquilo que ele próprio pretende afirmar. É como se nossa linguagem estivesse irremediavelmente aprisionada na mecânica clássica. (GRÜN, 2007, p. 56-57)

Essa falta de reflexão sobre a prática pedagógica e sobre a realidade humana proporciona, em geral, uma educação ambiental que se limita ao controle de comportamentos, à proteção de espécies e à motivação e sensibilização para a conservação da natureza, entre outras práticas que se pautam, apenas, na transmissão de informação e na mudança de comportamentos pontuais (TOZONI-REIS, 2007).

Esses aspectos também foram evidenciados na análise realizada pelo Projeto $O$ que fazem as escolas que dizem 
que fazem Educação Ambiental, o qual objetivou conhecer e avaliar as práticas de educação ambiental em 418 escolas públicas e particulares do ensino básico, localizadas em dois estados das cinco regiões brasileiras. O estudo evidenciou que as principais ações ambientais, que visam à articulação entre a escola e a comunidade,

se focam em palestras e eventos comemorativos, o que de certa forma evidencia que a escola acredita que a função primordial é sensibilizar e transmitir conhecimentos. (LOUREIRO et al., 2006a, p. 197)

É interessante destacar aqui algumas percepções sobre o que ocorre com a educação ambiental nos âmbitos da Universidade e da Escola Básica, com relação à falta de fundamentação mais elaborada e reflexiva para as práticas educativa e investigativa. Foi evidenciado, anteriormente, que grande parte das pesquisas acadêmicas no campo da educação ambiental se fundamenta em documentos oficiais e apresenta certa carência e sincretismo teórico-metodológico, o que, aos nossos olhos, é um fato preocupante.

Contudo, mais preocupante ainda é a percepção de que as práticas educativas dos professores das escolas básicas são mais reducionistas que as constatadas no âmbito acadêmico, pois uma parcela desses professores sequer conhece as leis que fundamentam os princípios da educação ambiental e, portanto, muitas vezes nem são capazes de identificar a educação ambiental em seu ambiente de trabalho. Essa constatação pode ser verificada neste fragmento:

É interessante constatar que os pesquisadores encontraram escolas em que os respondentes tinham dificuldades em definir a Educação Ambiental ou afirmar com convicção que esta existia ou não na instituição. Associado a isto, foi possível identificar casos em que os respondentes não mencionaram projetos e atividades que poderíamos classificar como sendo de Educação Ambiental (segundo princípios básicos contidos na Política Nacional de Educação e no Programa Nacional de Educação Ambiental, por exemplo), por não as considerarem como tal. (LOUREIRO et al., 2006b, p. 76)

Acreditamos que a falta de clareza sobre os princípios e conceitos da educação ambiental, que estão sendo apropriados e difundidos por diversas categorias de "intelectuais" (GRAMSCI, 1995) e reproduzidos por segmentos que estão a serviço do pensamento hegemônico - tais como os meios de comunicação, documentos oficiais, conferências e tratados internacionais, escolas e livros didáticos - tende a consolidar a ordem vigente e a problemática ambiental.

A constatação desse problema coloca para este estudo a necessidade de se refletir a educação ambiental no âmbito escolar: os professores $^{1}$ não podem realizar a educação ambiental aderindo à corrente hegemônica ou adotando expressões pedagógicas que são reproduzidas pelos meios de comunicação, cimentando um senso comum que fortalece a hegemonia da classe dominante do "bloco histórico vigente” (GRAMSCI, 1995).

Os princípios e conceitos da educação ambiental não podem ser considerados falsos e sem fundamentos, pois possuem uma lógica (a do capital), que objetiva a

\footnotetext{
${ }^{1}$ É importante destacar que, tal como foi evidenciado, existe certa carência de fundamentação teóricometodológica nas produções acadêmicas relativas à educação ambiental. Esse fato poderia sugerir a seguinte questão: por que o estudo se "limita" a denunciar que "o problema" recai sobre o professor da escola básica? Esta opção se deve à necessidade de concebê-lo como professor e pesquisador em sua práxis pedagógica, cuja realidade histórica coloca-o como o caráter mediador da educação no interior da sociedade (SAVIANI, 2005).
} 
concentração da riqueza nas mãos de quem detém o poder: "são formas de pensamento socialmente válidas, portanto objetivas, ajustadas às relações deste modo de produção das mercadorias” (MARX, 1984, p. 30). Essas formas justificam a acumulação de capital daqueles que detêm o domínio dos meios de produção. Nessas circunstâncias, temos que ultrapassar a "consciência normal dos próprios agentes de produção" (MARX, 1980, p. 30), por meio de uma consciência crítica e dialética do processo histórico.

A possibilidade de buscar um caminho que objetive o enfrentamento da problemática ambiental, tal como está colocada na atualidade, exige a necessidade de vislumbrar um horizonte que não esteja alinhado ao pensamento hegemônico que a reproduz e a intensifica; a contradição é fundamental.

É nesse sentido que defendemos a necessidade de uma postura radical no enfrentamento da problemática ambiental. Para não gerarmos interpretações dúbias diante desse posicionamento, recorreremos a uma importante definição do termo radical, formulada por Loureiro:

Radical não no sentido vulgar, encontrado no senso comum, de extremismo, de algo sem uma racionalidade consistente, mas no sentido proposto por Marx de atacar o problema pela raiz, sendo raiz o próprio ser humano, constituído e constituinte de um todo social. (LOUREIRO, 2004, p. 43)

Na busca de sanar o problema pela raiz, o pensamento marxiano pode contribuir para a compreensão da problemática ambiental, pois se constitui na análise crítica mais acurada do sistema capitalista, onde a "forma mais acabada do materialismo histórico como ciência da história é a caracterização do modo de produção capitalista" (LEFF, 2001, p. 115), que gerou a crise ecológica da modernidade.
À luz do problema exposto, chegamos à delimitação do objeto deste estudo: discutir a formação de professores a partir dos pressupostos da educação ambiental crítica na tentativa de articulá-la às formulações teóricas da Pedagogia Histórico-Crítica. O objetivo é apresentar uma reflexão que possa contribuir para o enfrentamento pedagógico da questão ambiental, especialmente no que diz respeito à formação dos professores que desenvolvem projetos e práticas pedagógicas que tematizam o ambiente no âmbito escolar.

\section{A práxis educativa no processo educativo ambiental}

As questões apresentadas colocam a necessidade de o professor refletir sobre a sua prática educativa e a importância da continuidade e da permanência de uma educação ambiental que instrumentalize (SAVIANI, 2005) a prática social dos sujeitos. Os projetos ambientais colocados em prática no âmbito escolar devem ser pautados em procedimentos teórico-metodológicos que vão além da ação em si, favorecendo a continuidade dos envolvidos no projeto e permitindo uma apropriação coletiva de instrumentos que lhes possibilitarão o enfrentamento da problemática ambiental. Essa dimensão pode contribuir para além das retóricas e dos discursos elaborados nas diversas ações ambientais no contexto escolar. É nesse sentido que Gramsci destaca:

Se o corpo docente é deficiente e o nexo instrução-educação é relaxado, visando a resolver a questão do ensino com esquemas de papel nos quais se exalta a educatividade, a obra do professor se tornará ainda mais deficiente: ter-se-á uma escola retórica, sem seriedade, pois faltará a corporeidade material do certo, e 
o verdadeiro será verdadeiro de palavra, ou seja, retórico. (GRAMSCI, 1995, p. 132)

A reflexão sobre a prática do professor pode, portanto, contribuir para a superação de práticas educativas ambientais que se mostram deficientes na medida em que legitimam o pensamento hegemônico da sociedade atual por meio de discursos e retóricas de uma "pedagogia redundante” (GRÜN, 2007).

Para analisar a prática, o professor não pode estar desprovido de uma teoria. Saviani (2005, p. 141) afirma:

Se a teoria desvinculada da prática se configura como contemplação, a prática desvinculada da teoria é puro espontaneísmo. É o fazer pelo fazer.

Visando à superação da prática pela prática, da ação como um fim em si mesmo, entendemos que a formação do professor deve ser pautada no pensar de sua prática educativa por meio de uma reflexão dialética, em movimento real com a teoria: é a práxis educativa. Acreditamos que, para o professor buscar o enfrentamento do estado das coisas e dos problemas encontrados no cotidiano escolar, é importante buscar fundamentos a partir da filosofia da práxis, entendendo-a como

[...] a teoria que está empenhada em articular a teoria e a prática, unificando-as na práxis. É um movimento prioritariamente prático, mas que se fundamenta teoricamente, alimenta-se da teoria para esclarecer o sentido, para dar direção à prática. Então, a prática tem primado sobre a teoria, na medida em que é originante. A teoria é derivada. Isto significa que a prática é, ao mesmo tempo, fundamento, critério de verdade e finalidade da teoria. A prática, para desenvolver-se e produzir suas conseqüências, necessita da teoria e precisa ser por ela iluminada. (SAVIANI, 2005, p. 141-142)
Percebemos, nesse fragmento, a importância da teoria para se pensar os problemas da realidade. É importante, pois, o professor pensar sobre os problemas de sua prática educativa, entendendo-os como determinações das contradições do seu tempo histórico, síntese de múltiplas determinações. É nesse contexto que a práxis educativa coloca a prática como ponto de partida e ponto de chegada do processo educativo (SAVIANI, 2005). Isso significa dizer que o professor, ao refletir sobre sua prática, necessita de um processo de análise, sendo que esta, por sua vez, pressupõe um método (enquanto teoria, e não apenas enquanto forma) para se pensar a realidade.

Essa concepção exige do professor uma consciência de seu dever e do conteúdo filosófico desse dever. Tal consciência não pode ser apenas uma expressão amesquinhada da consciência civil de toda a nação, como bem salienta Gramsci (1995) quando analisa os fins da escola elementar:

O conceito e o fato do trabalho (da atividade teórico-prática) é o princípio educativo imanente à escola elementar, já que a ordem social e estatal (direito e deveres) é introduzida e identificada na ordem natural pelo trabalho. $\mathrm{O}$ conceito do equilíbrio entre a ordem social e ordem natural sobre o fundamento do trabalho, da atividade teórico-prática do homem, cria os primeiros elementos de uma instituição do mundo liberta de toda magia ou bruxaria, e fornece o ponto de partida para o posterior desenvolvimento de uma concepção histórico-dialética do mundo, para compreensão do movimento e do devenir, para a valorização da soma de esforços e de sacrifícios que o presente custou ao passado e que o futuro custa ao presente, para a concepção da atualidade como síntese do passado, de todas as gerações passadas, que se projeta no futuro. (GRAMSCI, 1995, p. 130-131) 
Gramsci (2001) enfatiza que o reaprender a aprender sobre a prática social requer uma troca constante entre teoria e prática, no reconhecimento sobre a alienação e o domínio do produto histórico de nossa ação. Trata-se de uma transformação radical, revolucionária: uma nova proposta a todas as esferas do saber/fazer humanos.

Esse ponto de vista vincula a educação ambiental, especificamente, ao enfrentamento pedagógico da questão ambiental, pois a pedagogia

como ciência da e para a educação, se preocupa com a compreensão teórica e prática dos processos educativosformativos e diz respeito aos saberes e modos da ação voltados para a formação humana. (TOZONI-REIS, 2007, p. 186)

Os saberes voltados para a formação humana do indivíduo exigem que o professor tenha uma prática educativa focada nas relações sociais historicamente estabelecidas pelos sujeitos em sociedade. Essa condição exige um comprometimento político do professor que, adquirindo a condição de um agente social ativo, deve estar comprometido politicamente com as transformações da sociedade. Dessa forma, considerando que o trabalho educativo produz intencionalmente, em cada ser singular, o que de humanidade foi gerado e produzido histórica e coletivamente até o seu momento de realização (SAVIANI, 2005), o professor tem possibilidades de criar condições para que o sujeito se aproprie criticamente dos conteúdos culturais produzidos historicamente.

Acreditamos que o compromisso político do professor com a sociedade é fundamental para a elaboração de uma leitura crítica acerca do cotidiano escolar, embora somente esse compromisso não seja suficiente. Sobre esse aspecto, Saviani (2005, p. 36) chama a atenção para uma questão que tem passado despercebida para os professores, "a distinção entre sentido político em si e sentido político para si”. O compromisso político do professor muitas vezestemum sentidoem si, ou seja, éassumido apenas no nível do discurso. Entretanto, para que o professor tenha a reflexão sobre o seu papel diante de uma sociedade e em uma escola que é determinada (e não a sua consciência possível), é fundamental que tal compromisso seja assumido para si, ou seja, para ele mesmo enquanto sujeito do processo histórico, exercitando-o em sua prática educativa (SAVIANI, 2005).

É nesse sentido que entendemos que a filosofia da práxis pode contribuir para a formação do educador ambiental, na medida em que propõe repensar a prática e a teoria considerando-as uma unidade que coloca no horizonte o compromisso político do professor com a transformação das relações sociais que determinam a problemática ambiental na sociedade atual:

[...] se a educação é mediadora na atividade humana, articulando teoria e prática, a educação ambiental é mediadora da apropriação, pelos sujeitos, das qualidades e capacidades necessárias à ação transformadora responsável diante do ambiente em que vivem. Podemos dizer que a gênese do processo educativo ambiental é o movimento de fazer-se plenamente humano pela apropriação/transmissão crítica e transformadora da totalidade histórica e concreta da vida dos homens no ambiente.

(TOZONI-REIS, 2007, p. 218)

Com base nas discussões teórico-práticas expostas até aqui, podemos sintetizar a proposta de reflexão deste estudo: a formação de professores voltada para as práticas pedagógicas que tematizam o ambiente na educação escolar, na perspectiva teórica defendida neste estudo, não pode aceitar que os educadores ambientais incorporem 
os preceitos filosófico-políticos da corrente hegemônica sem uma reflexão dos ditames que os fundamentam e sem o compromisso político e a competência técnico-pedagógica (SAVIANI, 2005) para o enfrentamento da problemática ambiental.

Um dos desafios que se coloca aos educadores que compartilham dessa perspectiva é a tarefa intelectual de formular teoricamente na prática, pela práxis, o compromisso e o comprometimento de criar condições para uma ruptura com as relações sociais determinadas pelo capitalismo na prática educativa.

Esse desafio requer uma reflexão categórica com o objetivo de ultrapassar as práticas pontuais e imediatistas que querem mudar o pensamento e o comportamento sem mudar a realidade objetiva, ou seja, a organização social. Isso implica fundamentar o agir a partir de reflexões teóricas que qualifiquem a prática, sendo revistas por ela, ou seja, pela práxis, entendida como:

A atividade concreta pela qual o sujeito se afirma no mundo, modificando a realidade objetiva e sendo modificado, não de modo espontâneo, mecânico e repetitivo, mas reflexivo, pelo auto-questionamento, remetendo a teoria à prática. (LOUREIRO, 2004, p. 130)

Esse é o ponto decisivo e desafiador para aqueles que estão comprometidos com a educação ambiental crítica na perspectiva defendida neste estudo. Isso exige um pensamento reflexivo-dialético - ação-reflexão-ação - sobre a prática social, em um contexto onde a educação é entendida como mediação no seio da prática social global (SAVIANI, 2005).

\section{Conclusão}

Os pressupostos apresentados colocam-nos o desafio de enfrentarmos, efetivamente, os problemas fundamentais que determinam a prática do educador ambiental na sociedade atual.

Esse desafio coloca para o professor da escola pública a exigência de um posicionamento e de um compromisso político crítico com relação à sua função diante da sociedade. Neste caso, a função do professor está em enfrentar o fardo do seu tempo histórico (MÉSZÁROS, 2007), assumindo a responsabilidade de combater os fatores que determinam a miséria humana de seu tempo.

Muitas vezes, o professor, imerso em seu cotidiano, não reflete sobre o seu compromisso para com a sociedade, o que aponta para a exigência de uma formação que coloque como essencial, em seu horizonte, a necessidade de pensar a sua prática por meio de teorias que lhe possibilitem não apenas suportar o fardo de seu tempo histórico, mas enfrentá-lo. Essa perspectiva coloca a necessidade de concebê-lo como professor e pesquisador em sua práxis pedagógica

Diante das discussões apresentadas, concluímos, pois, que a filosofia da práxis torna-se imprescindível num processo educativo ambiental que coloque em seu horizonte a estratégia política como possibilidade de superação dos problemas sócio-ambientais.

Nossa expectativa é que algumas das considerações aqui apresentadas possibilitem o desenvolvimento e a produção de conhecimentos que contribuam para a luta por uma sociedade mais justa e igualitária, na qual o processo educativo possa pensar e organizar as ações ambientais, tendo como foco a busca da superação dos problemas da realidade humana. 
As reflexões apresentadas visaram a contribuir para o processo de formação dos professores da escola pública, no sentido de indicar um possível caminho para promover o acesso a sua tomada de consciência. Acreditamos que a educação ambiental crítica, por meio da práxis educativa, pode nos proporcionar condições para caminharmos em direção à supressão das práticas educacionais mediatizadas pela dicotomia entre a teoria e a prática, que esvaziam de sentido as ações em torno das práticas educativas ambientais, possibilitando a tomada de consciência do indivíduo e preparando-o para ações que visem à transformação.

\section{Referências}

GRAMSCI, Antonio. Os intelectuais e a organização da cultura. Tradução de Carlos Nelson Coutinho, 9. ed. Rio de Janeiro: Civilização Brasileira, 1995. 252p.

Cadernos do cárcere. Vol. 4. Rio de Janeiro: Civilização Brasileira, 2001.

GRÜN, Mauro. Ética e educação ambiental: a conexão necessária. 11. ed. Campinas, SP: Papirus, 2007.

GUIMARÃES, Mauro. Educação ambiental crítica. In: LAYRARGUES, Philippe Pomier (Org.). Identidades da educação ambiental brasileira. Brasília, MMA. Diretoria de Educação Ambiental, 2004. p. 25-34.

Armadilha paradigmática na educação ambiental. In: LOUREIRO, Carlos Frederico Bernardo; LAYRARGUES, Philippe Pomier; CASTRO, Ronaldo Souza de (Orgs.). Pensamento complexo, dialética e educação ambiental. São Paulo: Cortez, 2006. Cap. 1, p. 15-29.
LEFF, Enrique. Saber ambiental: sustentabilidade, racionalidade, complexidade, poder. 2. ed. Petrópolis: Vozes, 2001.

LOUREIRO, Carlos Frederico Bernardo. Trajetória e fundamentos da educação ambiental. São Paulo: Cortez, 2004.

. Problematizando conceitos: contribuições à práxis em educação ambiental. In: LOUREIRO, Carlos Frederico Bernardo; LAYRARGUES, Philippe Pomier; CASTRO, Ronaldo Souza de (Orgs.). Pensamento complexo, dialética e educação ambiental. São Paulo: Cortez, 2006. Cap. 4, p. 104-161.

. et al. Análise regional: região sudeste. In: TRAJBER, Rachel; MENDONÇA, Patrícia Ramos (Orgs.). Educação na diversidade: o que fazem as escolas que dizem que fazem educação ambiental. Brasília: Secretaria de Educação Continuada, Alfabetização e Diversidade, 2006a.

et al. Análise nacional: Conteúdos, gestão e percepção da educação ambiental nas escolas. In: TRAJBER, Rachel; MENDONÇA, Patrícia Ramos (Orgs.). Educação na diversidade: o que fazem as escolas que dizem que fazem educação ambiental. Brasília: Secretaria de Educação Continuada, Alfabetização e Diversidade, 2006b.

MARX, Karl. O capital. Rio de Janeiro: Civilização Brasileira, 1980. 6 v.

O capital. São Paulo: Difel, 1984.

Livro 3. Cap. 1.

MÉZÁROS, István. O desafio e o fardo do tempo histórico: o socialismo no século XXI. São Paulo: Boitempo 2007.

SANTOS, Milton. Técnica, espaço, tempo: globalização e meio técnico-científico informacional. São Paulo: HUCITEC, 1994. 
SAVIANI, Dermeval. Sobre a natureza e a especificidade da educação. In: SAVIANI, Dermeval. Pedagogia histórico-crítica: primeiras aproximações. 7. ed, Campinas: Autores Associados, 2000.

Educação: do senso comum a consciência filosófica. 14. ed. Campinas: Autores Associados, 2002.

Escola e democracia. 38. ed. Campinas: Autores Associados, 2006.

. Pedagogia histórico-critica. 9. ed. Campinas: Autores Associados, 2005.

TEIXEIRA, Lucas André et al. Referenciais teóricos da pesquisa em educação ambiental em trabalhos acadêmicos. In: ENCONTRO NACIONAL DE PESQUISA EM EDUCAÇÃO PARA A CIÊNCIA, 6, 2007, Florianópolis. Anais... São Paulo: ABRAPEC, 2007. 1 CD-ROM.

TOZONI-REIS, Marília Freitas de Campos. Educação ambiental: natureza, razão e história. Campinas: Autores Associados, 2004.

Contribuições para uma pedagogia crítica na educação ambiental: reflexões teóricas. In: LOUREIRO. C.F.B. A questão ambiental no pensamento crítico: natureza, trabalho e educação. Rio de Janeiro: Quartet, 2007, p. 177-221.

Enviado em: 13/10/2011

Aceito em: 27/10/2011 